\title{
Acute Zonal Occult Outer Retinopathy (AZOOR) in a patient with Hashimoto's thyroiditis
}

\author{
Retinopatia aguda zonal oculta externa em \\ uma paciente com tireoidite de Hashimoto
}

Luiz Reis Barbosa Júnior ${ }^{1}$, Ana Luiza Biancardi ${ }^{1}$, Márcio Penha Morterá Rodrigues¹, Eduardo de França Damasceno²

\begin{abstract}
Acute zonal occult outer retinopathy $(A Z O O R)$ is a rare disease characterized by an acute damage of one or more external retinal zones leading to the visual field or the visual acuity impairment associated with small or no changes in the fundus examination. The main clinical symptoms are scotomas and the sudden onset of photopsias. Abnormal findings on electroretinography and visual field defects are critical for the diagnosis. Central vision is usually preserved and the stabilization occurs in six months in most cases. The objective of this article is to describe a 24-month follow-up of a patient with AZOOR and correlate the findings with the typical features of this disease.

Keywords: Retinopathy; Electroretinography; Scotoma; Tomography, optical coherence; Retinal diseases; Visual acuity; Hashimoto disease; Case reports
\end{abstract}

\section{ReSUMO}

A retinopatia aguda zonal oculta externa (AZOOR) é uma doença rara, caracterizada por um dano agudo de uma ou mais zonas da retina externa que levam ao comprometimento do campo visual ou da acuidade visual, estando associada a pequenas ou nenhumas alterações no exame fundoscópico. Os principais sintomas clínicos são escotomas e o aparecimento súbito de fotopsias. Resultados anormais de defeitos de campo visual e eletrorretinografia são críticos para o diagnóstico. A visão central é geralmente preservada e a estabilização do quadro ocorre em seis meses na maioria dos casos. O objetivo deste artigo é descrever o "follow-up" de 24 meses de uma paciente com AZOOR e correlacionar os achados com as características típicas desta doença.

Descritores: Retinopatia; Electroretinografia; Escotoma; Tomografia de coerência óptica; Doenças da retina; Acuidade visual; Doença de Hashimoto; Relatos de casos

${ }^{1}$ Hospital Universitário Clementino Fraga Filho, Universidade Federal do Rio de Janeiro - Rio de Janeiro (RJ), Brazil;

${ }^{2}$ Universidade Federal Fluminense - Niterói (RJ), Brazil.

Os autores declaram não haver conflito de interêsses.

Recebido para publicação em 17/06/2015 - Aceito para publicação em 10/09/2015

Rev Bras Oftalmol. 2016; 75 (5): 409-11 


\section{INTRODUCTION}

$\mathbf{T}$ The acute zonal outer occult retinopathy (AZOOR) is characterized by sudden onset of photopsias and scotoma related to acute loss of function of one or more external retinal areas associated with minimal changes in the fundus examination, visual field defect related to the area of scotoma and an abnormal electroretinography (ERG). Generally, the clinical stabilization occurs in four to six months ${ }^{(1)}$.

Initially, the fundus examination is normal, however, in a long-term follow-up, most patients have zones of atrophy of the retinal pigment epithelium (RPE) similar to bone spicules observed in the retinitis pigmentosa ${ }^{(1)}$.

The etiology remains unclear but it is believed that there is an association with a prior viral disease with probable involvement of the photoreceptors. The possibility of an immune and an inflammatory response is also considered ${ }^{(2,3)}$.

Since the first description of AZOOR, some studies focused in various aspects of the disease, however, some issues are still misunderstood. (2) The objective of this article is to report the clinical features observed in a case of AZOOR during a 24-month follow-up.

\section{Case Report}

This brief report describes a 49-year-old woman with Hashimoto's thyroiditis who presented with a 9-month history of photophobia, colorful flashes and progressive visual field loss. She reported that the symptoms had started in both eyes simultaneously, as well as a viral infection and a severe stress preceding the ocular symptoms. The patient has never experienced anything like this previously and there is no family history of eye disease.

The examination revealed uncorrected visual acuity of 20/ $20 \mathrm{~J} 1$ in both eyes (OU) and normal extrinsic and intrinsic ocular motility. The Ishihara test, Pelli-Robson test, biomicroscopy and intraocular pressure were unremarkable in OU. The fundus examination showed a diffuse retinal pigment epithelium (RPE) atrophy sparing the macula and a normal vitreous and optic disc in OU (Figure 1).

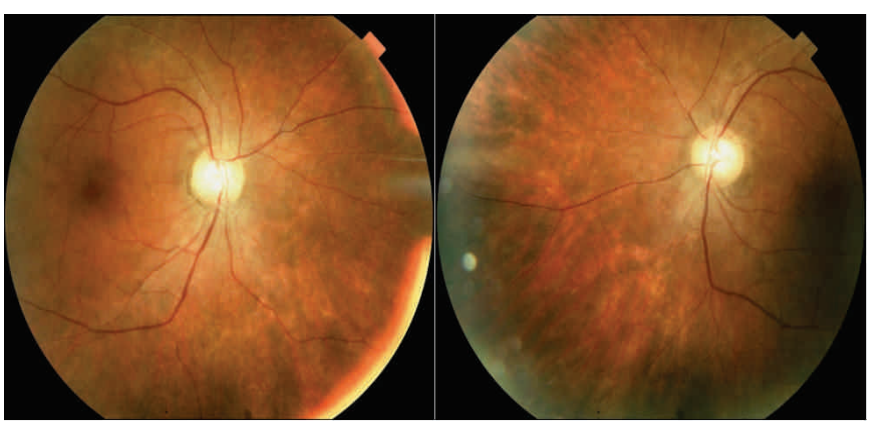

Figure 1: Fundus examination: diffuse retinal pigment epithelium atrophy sparing the macula in both eyes

Diagnostic tests were performed and the optical coherence tomography (OCT, Cirrus, Carl Zeiss Meditec, Dublin, CA) showed the thinning of the retina in the posterior pole, with disruption of the ellipsoid zone, except in the foveal area, where it remained intact in OU (Figure 2).

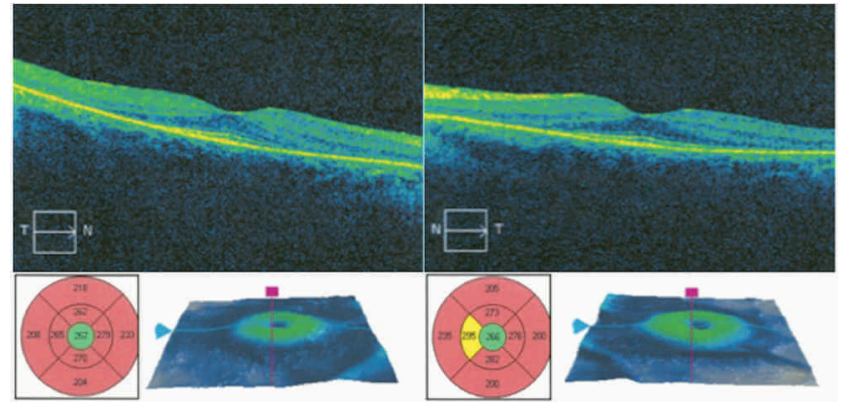

Figure 2: Optical Coherence Tomography: thinning of the retina in the posterior pole, with disruption of the fotorreceptor layer, except in the foveal area, where it remains intact

The fluorescein angiography revealed windows defects related to the RPE atrophy. Manual visual field test showed a diffuse contraction of the isopters in OU, however the central island of vision was preserved. (Figures 3 and 4) The visual evoked potential (VEP) was normal in OU and the full-field electroretinogram (ERG) in the scotopic and photopic phases was extinct in OU.

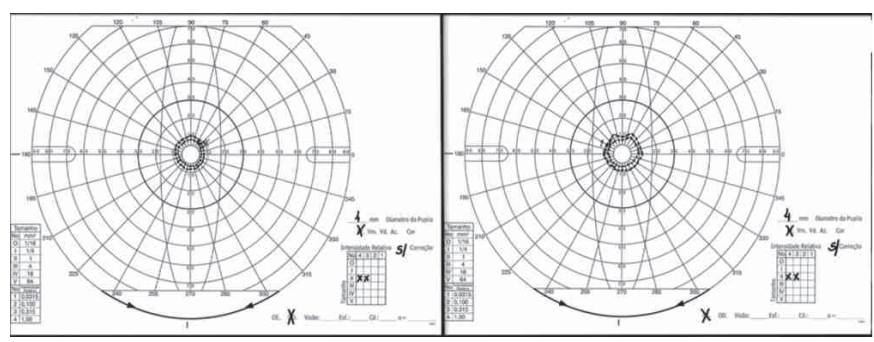

Figure 3: Manual Visual Field Test: diffuse contraction of the isopters with the preservation of the central island of vision in both eyes

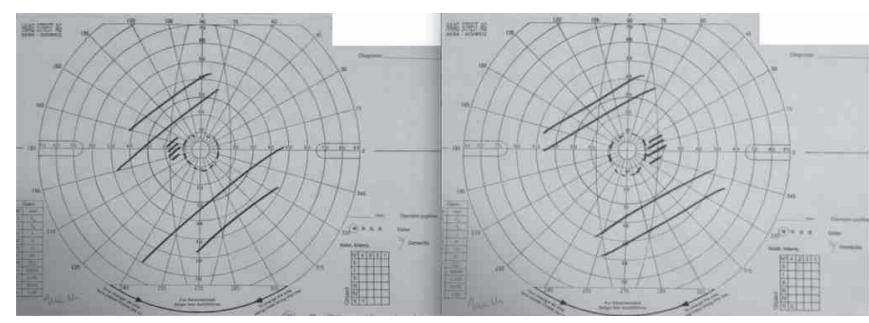

Figure 4: Manual visual field test after 2-year follow-up with the same characteristics maintaining the central island of vision in both eyes

Doppler ultrasound of carotid and vertebral arteries and brain and orbits contrast-enhanced nuclear magnetic resonance were unremarkable.

Based on the clinical findings and imaging guidelines, the diagnosis of AZOOR was done. The patient did not receive any treatment and the follow-up showed no progression of the visual field or visual acuity loss.

\section{Discussion}

The AZOOR usually affects myopic young female adults, with a predilection for caucasians. ${ }^{(1,3)}$ AZOOR has no family character, it is not associated with consanguinity and there is no report of an occupational predisposition. ${ }^{(1)}$ 
However, there is a strong evidence of association with autoimmune diseases such as Hashimoto's thyroiditis, myasthenia gravis, multiple sclerosis and transverse myelitis ${ }^{(1,3)}$. About $20 \%$ of the patients with AZOOR had a previous infection or a severe stress preceding the onset of the visual symptoms ${ }^{(1)}$.

At the initial presentation, unilateral involvement occurs in $60 \%$ of the cases, however, after long-term follow-up bilateral involvement is most common ${ }^{(1)}$.

The pathogenesis remains unclear. One possibility is a previous systemic viral infection affecting the photoreceptors located mainly at the ora serrata and close to the optic disc with related visual field defects. In these areas of the retina, the photoreceptors are not anatomically isolated from the systemic circulation, which explains the predilection for these regions. ${ }^{(1-5)}$

Another theory suggests that AZOOR is part of an autoimmune or inflammatory disease ${ }^{(6,7)}$, since there is a higher incidence in young female patients and the co-existence of other autoimmune diseases. However, some facts reject this theory, such as the asymmetric involvement, the failure of the treatment with corticosteroids, the absence of a family history and the absence of anti-retinal antibodies ${ }^{(1,3)}$.

Ninety $\%$ of the patients have sudden photopsias and a visual scotoma. ${ }^{(1)}$ Several patients reported that the visual field defect and the photopsia worse with brightness, stress and fatigue $^{(3)}$. The visual field loss is a characteristic finding in patients with $\mathrm{AZOOR}^{(1,3)}$. In most cases, the fovea is spared, which explains the preservation of the visual acuity. The temporal relationship between the onset of photopsia and the visual field loss is variable and may be simultaneously present. ${ }^{(1,3)}$ The AZOOR lesion typically has a peripapillary area of RPE atrophy, and changes are seen in other areas of the fundus as well. However, some early stage of AZOOR is classified as occult cases with a normal fundus ${ }^{(8)}$.

Usually, the visual acuity is minimally affected. ${ }^{(1,3)}$ However, in the subacute or chronic presentation, visual acuity was only mildly affected because of relative sparing at the fovea. In most cases the anterior segment is not affected. The afferent pupillary defect may be present ${ }^{(1,3)}$.

The diagnosis of AZOOR is based mainly on the manual visual field exam, fluorescein angiography, optical coherence tomography and electroretinography.

The most common finding in the visual field exam is the enlargement of blind spot. However, the visual field loss is typical and usually stabilized within 6 months at the onset of AZOOR with a recurrence rate of $31 \%{ }^{(1,3)}$. In a patient with photopsias and typical findings in manual field exam, some differential diagnoses should be reminded, such as cancer associated retinopathy (CAR), melanoma associated retinopathy (MAR) and neoplastic autoimmune retinopathy (npAIR). Furthermore, the differential diagnosis also includes many members of the white dot syndromes; therefore, the medical history and criteria already mentioned are essential to better diagnosis.

In most cases, the angiographic pattern is normal at the onset. A previous study observed that $52 \%$ of the eyes remain with no specific retinal lesions and $48 \%$ has abnormal retinal manifestations, such as the pattern of bone spicules that appeared isolated or associated with cystoid macular edema $(8 \%)$, retinal vascular narrowing, focal chorioretinal scars (4\%) and multifocal chorioretinal scars $(2 \%)$. $^{(1)}$.

Since AZOOR affects the photoreceptors outers segments, it is observed in the OCT focal irregularities or absence of the junction of the inner and outer photoreceptor segments (ellipsoid zone), attenuation or loss of the outer nuclear layer and consequent thinning of retina. ${ }^{(9-11)}$ An abnormal ERG is observed in most cases, and the diagnosis of AZOOR should be questioned if the patient has a normal ERG. ${ }^{(1,3,12)}$ No treatment is effective to avoid sequelae in patients with AZOOR. ${ }^{(1)}$ The use of systemic immunosuppressive therapy and corticosteroids remains unclear. $(10,13)$

This report alerts to the difficult diagnosis of AZOOR due to the lack of specific criteria. In general, a delay occurs in AZOOR diagnosis in most cases. AZOOR must be considered in all patients with acute visual field loss, photopsias, good visual acuity and a normal fundus examination. Moreover, the knowledge about the pathogenesis and treatment of the AZOOR must be improved.

\section{REFERENCES}

1. Gass JD, Agarwal A, Scott IU. Acute zonal occult outer retinopathy: a long-term follow-up study. Am J Ophthalmol. 2002;134(3):329-39.

2. Gass JD. Acute zonal occult outer retinopathy. Donders Lecture: The Netherlands Ophthalmological Society, Maastricht, Holland, June 19, 1992. J Clin Neuroophthalmol. 1993; 13(2):79-97.

3. Monson DM, Smith JR. Acute zonal occult outer retinopathy. Surv Ophthalmol. 2011; 56(1): 23-35.

4. Gass JD. Are acute zonal occult outer retinopathy and the white spot Syndromes (AZOOR Complex) specific autoimmune diseases? Am J Ophthalmol. 2003;135(3):380-1.

5. Ibironke JO, Gurwood AS. Acute zonal occult outer retinopathy: A case report. Optometry. 2010; 81(1):22-7.

6. Jampol LM, Becker KG. White spot syndromes of the retina: a hypothesis based on the common genetic hypothesis of autoimmune/ inflammatory disease. Am J Ophthalmol. 2003; 135(3):376-9.

7. Jampol LM, Wiredu A. MEWDS, MFC, PIC, AMN, AIBSE, and AZOOR: one disease or many? Retina. 1995;15(5):373-8.

8. Gass JD. The acute zonal outer retinopathies. AM J Ophthalmol. 2000;130(5):655-657.

9. Li D, Kishi S. Loss of photoreceptor outer segment in acute zonal occult outer retinopathy. Arch Ophthalmol. 2007;125(9):1194-200.

10. Spaide RF, Koizumi H, Freund KB. Photoreceptor outer segment abnormalities as a cause of blind spot enlargement in acute zonal occult outer retinopathy-complex diseases. Am J Ophthalmol. 2008; 146(1):111-20.

11. Fine HF, Spaide RF, Ryan EH. Acute zonal occult outer retinopathy in patients with multiple evanescent white dot syndrome. Arch Ophthalmol. 2009;127(1):66-70.

12. Keltner JL, Thirkill CE, Yip PT. Clinical and immunologic characteristics of melanoma-associated retinopathy syndrome: eleven new cases and a review of 51 previously published cases. J Neuroophthalmol. 2001; 21(3):173-87.

13. Tang J, Stevens RA, Okada AA, Chin M, Nussenblatt RB, Chan CC. Association of antiretinal antibodies in acute annular outer retinopathy. Arch Ophthalmol. 2008;126(1):130-2.

\section{Corresponding author:}

Luiz Reis Barbosa Júnior

Universidade Federal do Rio de Janeiro

Rua Rodolpho Paulo Rocco, n 255

Cidade Universitária, Ilha do Fundão

Rio de Janeiro - RJ - Brazil

Tel: (55 21) 3938-9600

E-mail: luiz_reis@hucff.ufrj.br 